PENENTUAN NASABAH PENERIMA REWARD PRODUK GOLD DENGAN METODE SIMPLE ADDITIVE WEIGHTING (SAW) STUDI KASUS : PT. PINJAM INDONESIA

Riki Ruli A. Siregar; Faizal Fachrurrozi

IMPLEMENTASI METODE BACKWARD CHAINING PADA DATA WAREHOUSE DAOP 1 JAKARTA PT. KAI (PERSERO) Rakhmat Arianto; Chandra Bagus Sugiarto

IMPLEMENTASI METODE DETEKSI TEPI CANNY PADA OBJEK SEBAGAI MODEL KEAMANAN APLIKASI PADA SMARTPHONE ANDROID

Abdul Haris; Andi Prasetyo

ANALISA DATA DAN PERANCANGAN APLIKASI SERVICE PELANGGAN PT. JNE UNTUK PENINGKATAN KUALITAS LAYANAN

Dewi Arianti Wulandari; Sonny Syahrindra Putra

JARINGAN AD-HOC VEHICULAR (VANET) : TINJAUAN TENTANG ARSITEKTUR, KARAKTERISTIK, APLIKASI, DAN PROTOKOL MEDIUMACCESS CONTROL (MAC)

Rosida Nur Aziza

PERANCANGAN APLIKASI PENJADWALAN MATA KULIAH MENGGUNAKAN METODE CONSTRAINT PROGRAMMING Syam Gunawan

RANCANGAN TATA KELOLA PEREMAJAAN RUANG KELAS DIREKTORAT PEMBINAAN SEKOLAH DASAR

Ratna Mutu Manikam; Purwanto

PENGEMBANGAN AMORIK MENGGUNAKAN METODE GARIS SINGGUNG TERHADAP DUA LINGKARAN DAN PERSAMAAN KURVA BEZIER ORDE DUA.

Darma Rusjidi

OPTIMALISASI PENGAMBILAN KEPUTUSAN PENILAIAN KINERJA DOSEN PADA PERGURUAN TINGGI ISLAM XYZ MENGGUNAKAN AHP (ANALYTICAL HIERARCHY PROCESS)

Rahma Farah Ningrum

PENGAMANAN SMS PADA TELEPON SELULER BERBASIS ANDROID MENGGUNAKAN ALGORITMA TRIPLE DES Raka Yusuf; $M$. Rival Suheri

APLIKASI LATIHAN SOAL UJIAN TEORI SURAT IZIN MENGEMUDI BERBASIS WEB Harni Kusniyati; Raka Yusuf; Andri Setiawan

RANCANG BANGUN SIMULASI TERJADINYA LISTRIK DENGAN SUMBER DAYA SAMPAH BERBASIS MULTIMEDIA (STUDI KASUS : TPST BANTAR GEBANG)

Yasni Djamain; Ika Fitriyani Putri

\begin{tabular}{|c|c|c|c|c|c|c|}
\hline \multirow{2}{*}{ 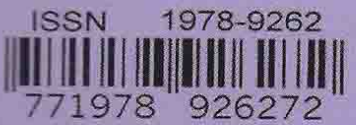 } & \multicolumn{6}{|c|}{ SEKOLAH TINGGI TEKNIK - PLN (STT-PLN) } \\
\hline & PETIR & VOL. 9 & NO. 1 & HAL. 1 - 87 & JAKARTA, MARET 2016 & ISSN $1978-9262$ \\
\hline
\end{tabular}




\title{
JARINGAN AD-HOC VEHICULAR (VANET) : TINJAUAN TENTANG ARSITEKTUR, KARAKTERISTIK, APLIKASI, DAN PROTOKOL MEDIUM ACCESS CONTROL (MAC)
}

\author{
Rosida Nur Aziza \\ Sekolah Tinggi Teknik - PLN, Jakarta \\ rosidayusuf@yahoo.com
}

\begin{abstract}
VANET (Vehicular Ad-hoc Network) is an ad-hoc wireless network which nodes are composed by mostly moving vehicles and infrastructure communications or access points along the road. It integrates adhoc networking, cellular technology, wireless LAN and other technologies, which include GPS(Global Positioning System), digital mapping, sensing technologies and advanced information processing tools to support Intelligent Traffic Systems (ITS). VANET is developed mainly to improve road safety and to increase the traffic efficiency. It is designed to support the exchange of warning messages among the vehicles to increase the passenger safety and other information related to VANET applications and services. To achieve these goals, there are several issues that should be addressed. One of these challenges is designing reliable and efficient Medium Access Control (MAC) protocol for VANET. Due to VANET's distinguishing characteristics, such as high mobility of the nodes, dynamic network topology, enough battery power, high processing power, etc, the MAC protocols designed for MANET (Mobile Ad-hoc Network) are not suitable for VANET. The research community has been working to develop MAC protocols appropriate for this ad-hoc network by proposing new design or modifying the existing one.

In this paper, the VANET's architecture, characteristics, applications and standard are discussed and then a comprehensive study of several MAC protocols available in the literature is presented.
\end{abstract}

Keywords : VANET, ad-hoc network, medium access control, ITS, DSRC

\section{ABSTRAK}

VANET adalah jaringan wireless ad-hoc yang memiliki node-node jaringan berupa kendaraan dan berbagai perangkat infrastruktur telekomunikasi pendukung. VANET menggabungkan beberapa teknologi, seperti jaringan ad-hoc, telekomunikasi selular, LAN tanpa kabel, GPS, pemetaan digital, teknologi penginderaan, dan kemampuan pemrosesan informasi yang canggih, untuk mewujudkan Intelligent Traffic Systems (ITS). Jadi, VANET dikembangkan terutama untuk meningkatkan keamanan di jalan raya dan efisiensi lalu lintas. Vanet dikembangkan untuk mendukung pertukaran pesan-pesan penting untuk peningkatan keselamatan penumpang, maupun informasi lain yang berkaitan dengan berbagai layanan dari VANET. Untuk mewujudkan hal tersebut, ada beberapa hal yang harus dipertimbangkan supaya VANET dapat beroperasi dengan baik. Salah satunya adalah bangaimana merancang protokol MAC untuk VANET yang efisien dan handal. Karena adanya beberapa karakteristik khusus VANET, antara lain mobilitas nodenode jaringan yang tinggi, topologi jaringan yang dinamis, persediaan daya yang cukup, dan kebutuhan akan kemampuan pemrosesan yang tinggi, menyebabkan protokol-protokol yang telah ada dan dibuat untuk jaringan mobile ad hoc, MANET, tidak sesuai untuk VANET. Beberapa riset dilakukan untuk merancang protokol MAC yang sesuai untuk lingkungan VANET.

Tulisan ini mengkaji beberapa aspek dari VANET, termasuk standar yang digunakan, arsitektur jaringan, dan beberapa karakteristik khusus VANET yang harus menjadi pertimbangan dalam perancangan protokol MAC yang sesuai untuk jaringan ad-hoc vehicular. Bagian selanjutnya berisi pembahasan mengenai beberapa usulan protokol MAC yang sesuai untuk VANET.

Kata Kunci : VANET, jaringan ad-hoc, kendali akses media, ITS, DSRC

\section{Pendahuluan}

VANET adalah jaringan komunikasi ad-hoc dengan node-node jaringan berupa kendaraankendaraan dan titik-titik akses atau infrastruktur telekomunikasi yang terdapat di sepanjang jalan. Pada jaringan ini, komunikasi yang terbentuk dapat berupa komunikasi antar kendaraan atau kendaraan dengan titik akses yang tersedia.
Jaringan ini merupakan cikal bakal dari ITS (Intelligent Traffic Systems) dikembangkan dengan mengacu pada standar IEEE 802.11p dan IEE 1609 , maupun standar yang telah ada sebelumnya (Teixeira et al., 2014). VANET diharapkan mampu menyediakan berbagai layanan yang dapat meningkatkan keselamatan di jalan raya dan memperbaiki efisiensi trafik lalu lintas. Contohnya, kendaraan yang terhubung pada jaringan ad-hoc 
ini dapat memberitahukan kendaraan lain tentang informasi perbaikan jalan yang berpotensi menimbulkan kecelakaan, pemberitahuan adanya kemacetan di suatu lokasi sehingga memberi kesempatan bagi pengendara-pengendara untuk mencari jalur alternatif, adanya aplikasi lampu rem otomatis, sampai penyediaan akses internet $d$ dalam kendaraan. Selain itu, VANET juga mendukung berbagai aplikasi yang dapat meningkatkan kenyamanan penupang.

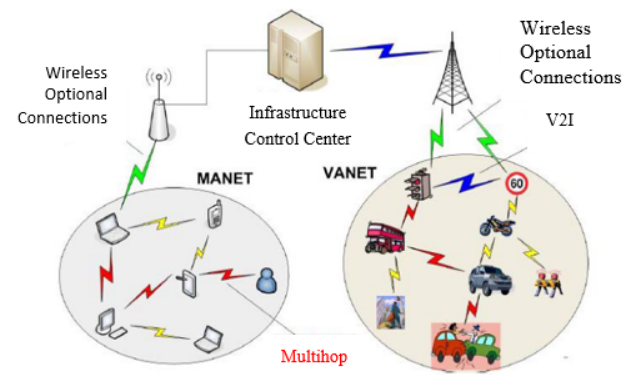

Gambar 1. MANET vs VANET (Gillani et al., 2015)

VANET memiliki prinsip yang sama dengan MANET, tetapi ada beberapa hal yang membedakannya dari MANET. Gambar 1 menunjukkan perbedaan antara VANET dengan MANET. Node-node pada jaringan VANET, yang berupa kendaraan, memiliki mobilitas tinggi dan bergerak dengan cepat, jika dibandingkan dengan node-node pada MANET. Akibatnya, topologi jaringan VANET ini mengalami perubahan yang terus menerus secara cepat. Waktu yang diperlukan untuk membangun dan melaksanakan komunikasi antar kendaraan, maupun kendaraan dengan jaringan infrastruktur telekomunikasi yang ada sangat terbatas. Topologi yang dinamis, ditambah dengan beberapa karakterisitik VANET lainnya menyebabkan munculnya kebutuhan akan protokol komunikasi yang baru atau pengembangan dari protokol yang sudah ada.

Beberapa riset dan studi telah dilakukan oleh pihak-pihak industri, akademisi, pemerintah nasional, maupun internasional untuk mewujudkan VANET. Banyak hal yang harus dipertimbangkan, termasuk merancang protokol-protokol yang sesuai untuk diterapkan di VANET. Beberapa proyek yang melakukan riset di bidang ini, antara lain : VII (Vehicle Infrastructure Integration Program) di Amerika Utara, VICS (Vehicle Information and Communication System) di Jepang, The FleetNet dan NoW (Network on Wheels) di Jerman, VICS (Vehicle Information and Communication System), konsorsium Car-2-Car Communication (Europe), IEEE dan ISO (Dass et al., 2012). Sementara itu, beberapa manufaktur mobil terkemuka di dunia, antara lain BMW, Mercedes, Fiat, Ford, Toyota, juga sedang berusaha membuat prototipe mobil yang dilengkapi dengan kemampuan komunikasi, seperti GPS, WiFi (IEEE $802.11 \mathrm{a} / \mathrm{b} / \mathrm{g}$ ), DSRC (IEEE 802.11p), sehingga dapat memenuhi syarat sebagai node dari VANET (Gillani, 2015).
Menentukan algoritma atau protokol MAC yang sesuai untuk VANET adalah salah satu topik yang banyak dibahas dan menjadi obyek penelitian. Protokol MAC adalah protokol yang bertugas utama mengatur akses ke kanal komunikasi yang dipakai bersama. Tulisan ini akan membahas mengenai VANET dan beberapa aspek dasarnya, serta beberapa usulan protokol MAC untuk VANET. Protokol-protokol yang akan dikaji meliputi protokol MAC dengan mekanisme contention-based, contention-free, maupun gabungan dari keduanya.

\section{Protokol MAC dan Alokasi Kanal}

Media transmisi atau kanal yang disediakan untuk komunikasi pada suatu jaringan memiliki kapasitas terbatas. Jumlah node atau pengguna yang tergabung pada suatu jaringan, pada umumnya, melebihi kapasitas media transmisi yang tersedia. Hal ini terutama berlaku untuk jaringan wireless, dengan media transmisi berupa gelombang elektromagnetik dengan jangkauan frekuensi terbatas, yang harus digunakan bersama oleh banyak pengguna. Oleh karena itu, diperlukan suatu mekanisme yang dapat mengatur penggunaan media transmsi tersebut secara adil untuk semua node. Protokol yang menyediakan fungsi pengaturan akses ke media transmisi tersebut dikenal sebagai protokol MAC. Pada Arsitektur Protokol OSI, protokol MAC ini terletak pada sub lapisan kedua, yaitu lapisan yang menghubungkan lapisan fisik dengan sub lapisan LLC (Logical Link Control).

Secara garis besar, ada dua cara pangalokasian kanal komunikasi untuk banyak pengguna. Yang pertama adalah dengan metode alokasi statis. Yaitu, dengan memberi jatah penggunaan kanal komunikasi yang sama untuk semua pengguna. Misalkan, pada teknik FDMA (Frequency Division Multiple Access), kanal dengan lebar frekuensi tertentu akan dibagi sesuai dengan jumlah pengguna yang terhubung ke jaringan tersebut. Jadi masing-masing pengguna dapat melaksanakan komunikasi pada waktu bersamaan pada daerah frekuensi yang berbeda. Metode statis ini disebut juga metode contention free.

Mode alokasi yang kedua adalah dinamis. Tidak ada kanal khusus untuk tiap pengguna jaringan. Jadi, beberapa node yang ingin berkomunikasi harus bersaing untuk mendapatkan akses ke kanal transmisi. Node yang menang dapat menggunakan kanal selama periode waktu tertentu. Metode ini disebut dengan contentionbased.

\section{Vehicle Ad-hoc Network (VANET)}

\subsection{Arsitektur VANET}

Komponen penyusun VANET secara garis besar dapat dikelompokkan menjadi kelompok mobile dan kelompok infrastruktur. Kelompok pertama meliputi berbagai jenis kendaraan dan alat komunikasi mobile, termasuk piranti navigasi dan telepon genggam. Kelompok infrastruktur terdiri 
dari berbagai infrastruktur yang terlibat dalam VANET, seperti titik akses, gateway dan lain sebagainya. Adapun gambar 2 menunjukkan contoh arsitektur VANET dengan berbagai komponen penyusunnya berdasar referensi dari C2C CC (Car2Car Communication Contortium).

Berdasar gambar tersebut, setiap kendaraan yang tergabung dalam VANET harus dilengkapi dengan On-Board Unit (OBU) dan Application Unit (AU). OBU bertindak sebagai terminal sekaligus router wireless. Titik akses infrastruktur pada VANET dikenal dengan istilah Road Side Unit (RSU). RSU ditempatkan di lokasi-lokasi strategis di sepanjang jalan, misalkan di persimpangan jalan atau pada lampu lalu lintas. Dalam jaringan vehicular ini, OBU dapat dianggap sebagai node yang bergerak dan RSU adalah node yang diam (statis). RSU dapat tergabung ke Internet melalui Internet Gateway dan OBU dapat terhubung ke Internet melalui RSU atau Hotspot (HS).

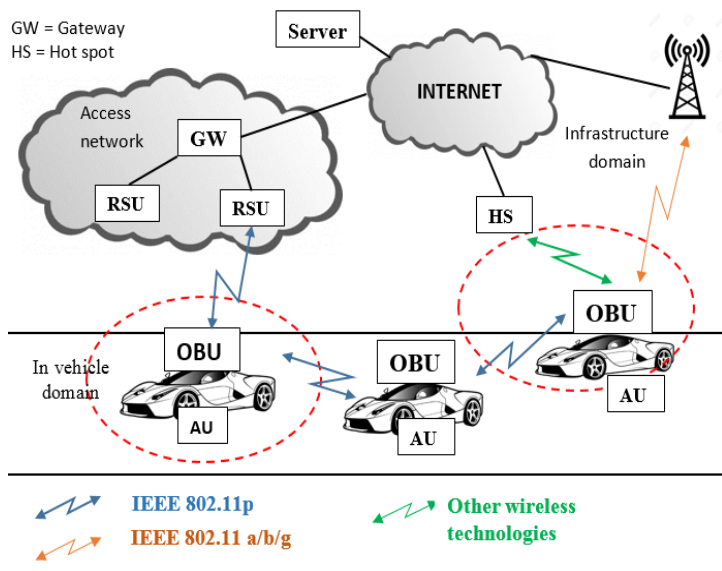

Gambar 2. Arsitektur VANET menurut C2C CC

Ada empat tipe komunikasi pada VANET, yaitu komunikasi In-vehicle, Vehicle-to-vehicle (V2V), Vehicle-to-road infrastructure (V2I atau V2R), dan Vehicle-to-broadband (V2B) (Liang et al., 2015). Komunikasi In-vehicle menyediakan berbagai informasi yang berhubungan dengan kejadian di dalam suatu kendaraan, misalnya: kecepatan dan posisi kendaraan, informasi apakah pengendara mengantuk atau mengalami kelelahan. V2V mengatur bagaimana kendaraan-kendaraan dapat saling bertukar informasi yang berhubungan dengan lalu lintas. Komuniksi V2I menghubungkan kendaraan dengan berbagai perangkat infrastruktur, termasuk RSU. V2I memungkinkan pengendara menerima informasi tentang kondisi lalu lintas, cuaca, dan informasi lain dari sensor yang tergabung dalam VANET secara real time. Tipe komunikasi V2B menghubungkan kendaran dengan jaringan wireless broadband, seperti 3G/4G. Dari gambar 2 di atas, dapat diketahui bahwa komunikasi V2V dilaksanakan menggunakan standar wireless atau protocol yang khusus dikembangkan untuk VANET, seperti IEEE 802.11p. Sedangkan, komunikasi dari kendaraan ke RSU atau ke perangkat infrastruktur jaringan yang lain dapat dilakukan menggunakan berbagai teknologi wireless lain yang tersedia saat ini.

\subsection{Karakteristik VANET}

Ada beberapa karakteristik VANET yang mempengaruhi perancangan protokol MAC yang sesuai untuk VANET, yaitu (Almalag et al., 2013 dan Daas et al., 2012):

\section{a. Jumlah Node}

Jumlah dan kepadatan node pada VANET bervariasi. Jumlah node bisa sangat besar di daerah perkotaan pada jam sibuk. Namun jumlah node VANET bisa sangat sedikit di daerah pedesaan dengan jumlah mobil yang dilengkapi kemampuan komunikasi sangat terbatas. Protokol MAC harus mampu bekerja dengan baik pada kedua keadaan tersebut. Tantangan untuk daerah dengan kepadatan node rendah adalah kemungkinan diskoneksi jaringan VANET.

\section{b. Mobilitas node yang tinggi}

Kendaraan sebagai node dari VANET dapat bergerak dengan kecepatan tinggi, lebih dari 100 $\mathrm{km} / \mathrm{jam}$. Hal ini sering menyebabkan diskoneksi antar node. Jika, dimisalkan, suatu kendaraan yang melaju kencang berkomunikasi dengan kendaraan yang berjalan lambat, maka link komunikasi yang terbentuk akan berumur pendek. Hubungan akan terputus karena jarak yang memisahkan kedua node tersebut semakin besar. Protokol MAC harus dapat bekerja baik dengan umur link komunikasi yang singkat.

\section{c. Topologi jaringan yang berubah-ubah}

Karena node-node VANET memiliki mobilitas tinggi, maka topologi jaringan VANET yang terbentuk juga terus-menerus mengalami perubahan

\section{d. Topologi jaringan yang dapat diprediksi}

Walaupun node-node VANET banyak bergerak, namun pergerakannya dibatasi oleh topologi jalan raya yang dilaluinya.

\section{e. Ketersediaan informasi lokasi}

Informasi lokasi dari node yang diberikan oleh GPS dapat mengurangi waktu pengiriman data dan meningkatkan throughput jaringan. Selain itu, informasi posisi dan kecepatan node-node melaju juga dapat membantu memperkirakan pola mobilitas dari node-node tersebut.

\section{f. Daya dukung infrastruktur}

Dukungan dari berbagai perangkat infrastruktur yang terdapat di sepanjang jalan dapat meningkatkan kinerja dari protokol MAC.

\section{g. Sumber tenaga/batere yang tak terbatas}

Dibandingkan node-node MANET yang memiliki daya listrik terbatas, node VANET memiliki daya yang tidak terbatas. Batere dari kendaraan yang melaju mampu menyediakan daya terusmenerus untuk mengaktifkan peralatan komunikasi node tersebut. 
Selain tujuh karakteristik di atas, ada faktor lain yang harus dipertimbangkan oleh protokol MAC, yaitu pengiriman pesan sesuai prioritas. Ada beberapa jenis pesan yang dipertukarkan di VANET. Masing-masing pesan memerlukan penanganan yang tidak sama. Misalkan, pesan yang berhubungan dengan keselamatan pengendara dan penumpang kendaraan tidak memerlukan pesat data yang tinggi, melainkan ketepatan waktu. Ada aturan waktu delay maksimum yang harus dipenuhi untuk jenis pesan tersebut (hard delay constraint).

\subsection{Jenis Pesan dan Aplikasi VANET}

Pesan-pesan yang dikomunikasikan antar kendaraan atau kendaraan dengan RSU, dapat dikelompokkan menjadi 4 bagian (Rathore et al., 2010). Kelompok-kelompok tersebut memiliki prioritas yang tidak sama. Protokol MAC harus mampu mendeteksi jenis pesan yang diterima dan memperlakukan pesan tersebut sesuai dengan prioritasnya. Adapun 4 jenis pesan tersebut adalah sebagai berikut :

a. Emergency and Warning Message

Pesan ini dapat berisi informasi penting yang diharapkan dapat mencegah terjadinya kecelakaan, atau peringatan tentang berbagai kejadian di jalan raya yang perlu diketahui oleh pengguna jalan raya. Pesan jenis ini dikirimkan ke kendaraan-kendaraan berdasarkan adanya kejadian membahayakan atau berpotensi menimbulkan bahaya yang terdeteksi oleh suatu atau beberapa node. Kelompok pesan ini memiliki prioritas tertinggi. Kelompok ini tidak memerlukan pesat data yang tinggi karena ukuran pesan yang dikirimkan pendek. Yang diutamakan adalah waktu pengiriman pesan ke node yang dituju.

b. Routing and Basic Safety Message

Pesan ini biasanya dikirimkan oleh suatu node secara periodik, broadcast dan berisi berbagai informasi tentang status node tersebut, antara lain: posisi, kecepatan, dan arah node.

c. Infotainment Message

Pesan ini berisi informasi yang dapat memberikan kenyamanan pengendara, maupun penumpang kendaraan. Pesan berisi info tentang keberadaan stasiun pengisian bahan bakar dan rumah makan yang terdekat dan paket data streaming radio/TV, adalah contoh pesan yang termasuk kelompok ini. Kelompok ini tidak memerlukan prioritas tinggi, namun seringkali membutuhkan kecepatan transmisi yang tinggi .

d. Inter-personal message

Berisi informasi tentang pengendara atau penumpang kendaraan.

Selain tipe pesan, protokol MAC juga harus memperhatikan beberapa aplikasi yang akan disediakan oleh VANET. Aplikasi-aplikasi tersebut beragam dan memerlukan perlakuan dari protokol MAC yang tidak sama karena memiliki prioritas yang berbeda-beda. Secara garis besar, aplikasi- aplikasi VANET dapat dikelompokkan menjadi 2 bagian, yaitu aplikasi yang berkaitan dengan keselamatan dan aplikasi yang tidak menyangkut keselamatan.

\subsubsection{Safety Application}

Kelompok ini meliputi beberapa aplikasi yang berkaitan dengan keselamatan dan manajemen lalu lintas. Adapun contoh beberapa aplikasi yang termasuk kategori ini adalah sebagai berikut (Kumar et al., 2013 dan Raw et al., 2013):

a. Collision Avoidance

Aplikasi yang dapat menghindarkan satu atau beberapa kendaraan dari kecelakaan. Pesan yang dikirim harus dapat diterima dengan cepat, sehingga pengendara memiliki waktu untuk bertindak menghindari kecelakaan.

b. Cooperative Driving

Kendaraan dapat saling mengirimkan informasi yang berkaitan dengan keadaan lalu lintas.

c. Post Crash Notification

Kendaraan yang terlibat kecelakaan dapat memberitahukan kendaraan lain atau pihak yang berwenang tentang lokasi dan keadaannya.

d. Road Hazard Control Notification

Aplikasi yang dapat digunakan untuk memberitahukan tentang kondisi jalan yang dilalui, misalnya adanya tanah longsor yang menghalangi jalan, lubang , tikungan ganda, atau tanjakan yang tajam.

e. Traffic Optimisation

Adanya sinyal/pesan yang dikirimkan secara broadcast dengan tujuan mengoptimalkan kondisi lalu lintas. Misalkan, pesan yang mengumumkan adanya kemacetan di suatu lokasi. Kendaraan-kendaraan yang menangkap pesan tersebut dapat mencari jalan alternatif dan menghindari lokasi kemacetan.

f. Traffic Vigilance

Aplikasi ini dapat diletakkan pada RSU-RSU yang terletak di lokasi strategis untuk mendeteksi adanya pelanggaran lalu lintas yang dilakukan oleh pengendara kendaraan.

\subsubsection{Non-safety Application}

Aplikasi yang tidak berkaitan dengan keselamatan ini disediakan, terutama untuk meningkatkan kenyamanan dan kemudahan bagi pengendara dan penumpang kendaraan. Beberapa contoh aplikasi yang ditawarkan adalah (Gillani et al., 2015 dan Kumar et al., 2013):

a. Internet Access

Node-node pada VANET dapat terhubung ke Internet melalui RSU.

b. Digital Map Downloading

Aplikasi ini dapat menyediakan peta-peta digital yang diperlukan pengendara yang akan bepergian ke tempat yang baru.

c. Real Time Video Relay

Memberikan layanan penayangan video OnDemand bagi penumpang di dalam kendaraan. 
d. Parking Availability

Aplikasi yang dapat memberikan informasi adanya lokasi-lokasi kosong untuk parkir, terutama di kota-kota besar.

e. Electronic Toll Collection

Aplikasi ini menyediakan layanan penarikan biaya jalan tol secara elektronik via OBU.

e. Value Added Advertisement

Aplikasi dari penyedia layanan yang berusaha menarik pelanggan ke tempat usaha mereka. Aplikasi ini berisi iklan dari berbagai toko, rumah makan, SPBU ke kendaraankendaraan yang berada di sekitarnya. Layanan ini dapat diperoleh tanpa harus terhubung ke Internet.

\subsection{IEEE 802.11p}

WAVE (Wireless Ad-hoc Vehicular Environments) adalah arsitektur protokol yang dikembangkan oleh IEEE untuk jaringan ad-hoc vehicular. WAVE juga dikenal dengan istilah DSRC (Dedicated Short-Range Communication). Arsitektur ini meliputi 2 standar, yaitu IEEE $802.11 \mathrm{p}$ untuk lapisan protokol bawah dan kelompok standar IEEE 1609 untuk lapisan protokol yang lebih atas. Tumpukan protokol komunikasi berdasarkan WAVE ditunjukkan oleh tabel 1.

Tabel 1. Arsitektur Protokol WAVE

\begin{tabular}{|c|c|}
\hline Safety-related Application & Non-safety Application \\
\hline $\begin{array}{l}\text { Transport and Network Layer } \\
\text { IEEE } 1609.3\end{array}$ & $\begin{array}{l}\text { Transport Layer } \\
\text { TCP/UDP }\end{array}$ \\
\hline $\begin{array}{l}\text { Security } \\
\text { IEEE } 1609.2\end{array}$ & $\begin{array}{l}\text { Network Layer } \\
\text { IPv6 }\end{array}$ \\
\hline $\begin{array}{l}\text { LLC Sublayer } \\
\text { IEEE } 802.11\end{array}$ & \\
\hline $\begin{array}{l}\text { MAC Sublayer Extension } \\
\text { IEEE } 1609.4\end{array}$ & \\
\hline $\begin{array}{l}\text { MAC Sublayer } \\
\text { and Physical Layer } \\
\text { IEEE } 8022.11 p\end{array}$ & \\
\hline
\end{tabular}

Sesuai dengan tabel di atas, IEEE 802.11p merupakan standar yang berkaitan dengan lapisan fisik dan sub lapisan MAC yang bawah. Pada lapisan fisik, IEEE 802.11p menggunakan teknik modulasi sinyal OFDM (Orthogonal FrequencyDivision Multiplexing). Alokasi frekuensi yang digunakan untuk implementasi DSRC di EropaJepang berada pada $5,8 \mathrm{GHz}$. Sedangkan, implementasi DSRC di US menggunakan spektrum frekuensi sebesar $75 \mathrm{MHZ}$ pada daerah frekuensi $5,9 \mathrm{GHz}$, tepatnya antara $5.850-5.925$ $\mathrm{MHz}$. Spektrum tersebut dibagi menjadi 8 kanal, 1 kanal $5 \mathrm{MHZ}$ untuk guard band dan 7 kanal untuk transmisi masing-masing sebesar $10 \mathrm{MHz}$. Dari ketujuh kanal tersebut, 1 kanal difungsikan sebagai kanal kendali (Control Channel, $\mathrm{CCH}$ ) dan 6 kanal untuk kanal servis (Service Channel, $\mathrm{SCH}$ ). $\mathrm{CCH}$ atau kanal 178, seperti ditunjukkan pada Gambar 3 , digunakan untuk mengirim pesan-pesan kendali. Kanal 172,174, 176, 180,182,184 digunakan sebagai kanal SCH. Kanal nomor 172 dan 184 digunakan untuk pengiriman pesan-pesan penting yang berhubungan dengan keselamatan. Pasangan kanal 174-176 dan 180-182 dapat digunakan bersama sebagai kanal berukuran 20 $\mathrm{MHz}$, yaitu kanal nomor 175 dan kanal 181. Pada lapisan MAC, IEEE $802.11 \mathrm{p}$ mengusulkan protokol EDCA (Enhanced Distributed Coordination Access) yang merupakan pengembangan dari mekanisme CSMA/CA (Carrier Sense Multiple Access with Collision Avoidance)

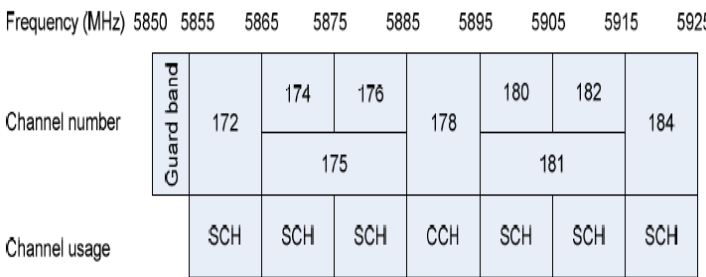

Gambar 3. Alokasi frekuensi DSRC (Li, 2012)

Standar IEEE 802.11p ini diharapkan mampu mendukung komunikasi V2V dan V2I dengan jarak maksimum $1000 \mathrm{~m}$ dan dengan kecepatan kendaraan, absolut maupun relative, sebesar $30 \mathrm{~m} /$ menit $(108 \mathrm{~km} / \mathrm{jam})$ pada beberapa macam kondisi, yaitu : pedesaan, perkotaan dan jalan raya (Teixeira et al., 2014). Kanal yang berukuran 10 $\mathrm{MHz}$ mampu menghasilkan pesat data antara 3-27 Mbps, sedangkan kanal $20 \mathrm{MHz}$ dapat menghasilkan pesat data maksimum sebesar 54 Mbps.

\section{Persyaratan Protokol MAC untuk VANET}

Seperti telah dijelaskan pada bab 3, VANET memiliki beberapa karakteristik yang membedakannya dengan MANET maupun jaringan wireless lainnya. Diperlukan pengembangan, modifikasi, bahkan pembuatan desain protokol MAC baru yang mampu menangani berbagai karakteristik khas VANET tersebut. Menurut Leng,S. et al. (Leng et al., 2015), ada beberapa persyaratan yang harus diperhatikan dalam perancangan protokol MAC untuk VANET, yaitu :

a. Protokol MAC yang dikembangkan harus dapat mendukung aplikasi yang berkaitan dengan keselamatan maupun yang bukan. Protokol MAC harus memperhatikan kehandalan dan waktu pengiriman (delay) yang singkat untuk aplikasi jenis pertama. Sedangkan untuk aplikasi tak terkait keamanan, titik berat protokol MAC ada pada penggunaan bandwidth yang tersedia seefisien mungkin untuk menambah kenyamanan berlalu lintas.

b. Mampu beroperasi dengan efisien pada komunikasi point-to-point maupun point-tomultipoint. Mode komunikasi point-to-point dilakukan apabila pesan dikirimkan ke node tujuan tertentu. Sedangkan pada komunikasi point-to-multipoint atau broadcast, pesan dikirimkan ke banyak node. Pada VANET, mode komunikasi broadcast banyak dilakukan 
untuk pengiriman pesan yang berhubungan dengan keselamatan maupun informasi lainnya.

c. Protokol MAC dapat beradaptasi dengan mode pengiriman pesan yang single hop dan multi hop. OBU pada VANET berlaku sebagai terminal sekaligus router wireless, oleh karena itu komunikasi antar kendaraan (IVC) dan kendaraan dengan infrastruktur (V2I ) dapat berlangsung secara single hop maupun multi hop.

Selain hal-hal di atas, protokol MAC untuk VANET harus dapat memanfaatkan bandwidth yang tersedia seefisien mungkin, memiliki kemampuan menangani trafik komunikasi yang ringan maupun yang berat (scalability), dan mampu menangani problem hidden node, yaitu node yang terlihat oleh RSU tetapi tidak terlihat oleh nodenode lain yang terkoneksi ke RSU tersebut maupun exposed node. Node-node pada VANET yang selalu bergerak menyebabkan waktu node untuk tetap terhubung ke RSU yang sama menjadi pendek. Jadi, diperlukan juga protokol yang memiliki mekanisme handoff yang efisien (Raw, 2013). Sebagian besar komunikasi yang berlangsung pada VANET dilakukan secara broadcast melalui kanal bersama dan hal ini dapat menyebabkan beban trafik komunikasi menjadi berat. Walaupun dalam kondisi trafik yang berat, protokol MAC untuk VANET tetap dituntut untuk dapat menyampaikan pesan yang sangat penting dalam waktu yang batas maksimalnya telah ditentukan.

\section{Protokol-protokol MAC untuk VANET}

Beberapa protokol MAC untuk VANET yang dibahas dalam bab ini adalah Enhanced Distributed Coordination Access (EDCA), Selforganizing Time Division Multiple Access (STDMA), RSU centric Cluster-based MAC (CMAC). Masing-masing proto-kol MAC tersebut mewakili 3 kategori mekanisme akses media yang ada : contention-base, contention-free, dan hybrid, atau campuran dari keduanya. EDCA yang berbasis CSMA/CD termasuk protokol contentionbased. STDMA merupakan contoh dari protokol contention-free dan menggunakan teknik TDMA, sedangkan CMAC termasuk kelompok protokol yang menggabungkan TDMA, FDMA dan mekanisme contention based. Kemudian dilanjutkan dengan ulasan singkat beberapa desain protokol MAC untuk VANET yang lainnya.

\subsection{EDCA}

EDCA adalah algoritma MAC yang diusulkan oleh standar IEEE 802.11p. Algoritma ini, pada dasarnya, merupakan pengembangan dari protokol DCF (Distributed Coordination Function) dengan tambahan QoS. DCF adalah protokol MAC yang menggunakan algoritma CSMA/CA. Jadi, EDCA adalah protokol MAC yang berbasis CSMA/CA dengan kemampuan menangani trafik data sesuai dengan prioritasnya.
Pada CSMA/CA, suatu node jaringan yang akan melakukan transmisi harus memeriksa kanal atau media transmisi selama periode waktu tertentu, yang disebut arbitration interframe space (AIFS), untuk menentukan apakah kanal kosong atau sibuk. Jika selama periode AIFS tersebut kanal tidak terpakai, maka node dapat segera mengirimkan datanya. Jika kanal sibuk, maka node akan menjalankan prosedur backoff. Prosedur backoff pada IEEE 802.11 adalah sebagai berikut : 1. Pilih bilangan bulat antara 0 sampai $\mathrm{CW}$, dengan CW adalah nilai maksimum dari Contention Wndow.

2. Jika kanal kosong, kurangkan nilai backoff sebanyak 1 per slot waktu.

3. Ulangi langkah kedua sampai nilai backoff $=0$, lalu lakukan transmisi.

Pada mode komunikasi broadcast, prosedur backoff hanya dijalankan sekali pada saat awal node memeriksa kanal. Pada komunikasi point-topoint atau unicast, prosedur backoff dijalankan lebih dari sekali, yaitu pada saat awal dan ketika node pengirim pengirim menunggu pesan ACK dari node tujuan. Setelah mengirimkan pesan, node akan menunggu jawaban berupa pesan ACK dari node tujuan. Jika sampai waktu tertentu node tidak menerima ACK, maka prosedur backoff akan dijalankan. Gambar 4 dan 5 menunjukkan diagram mekanisme akses media pada mode komunikasi broadcast maupun unicast sesuai dengan standar IEEE 802.11-2012.

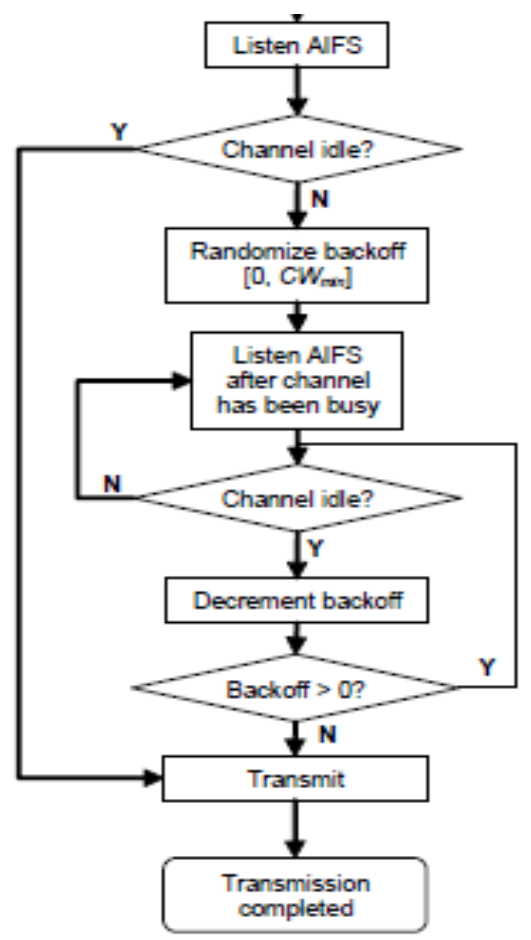

Gambar 4. Mekanisme akses media pada komunikasi broadcast menurut IEEE 802.11-2012 (ETSI, 2013) 


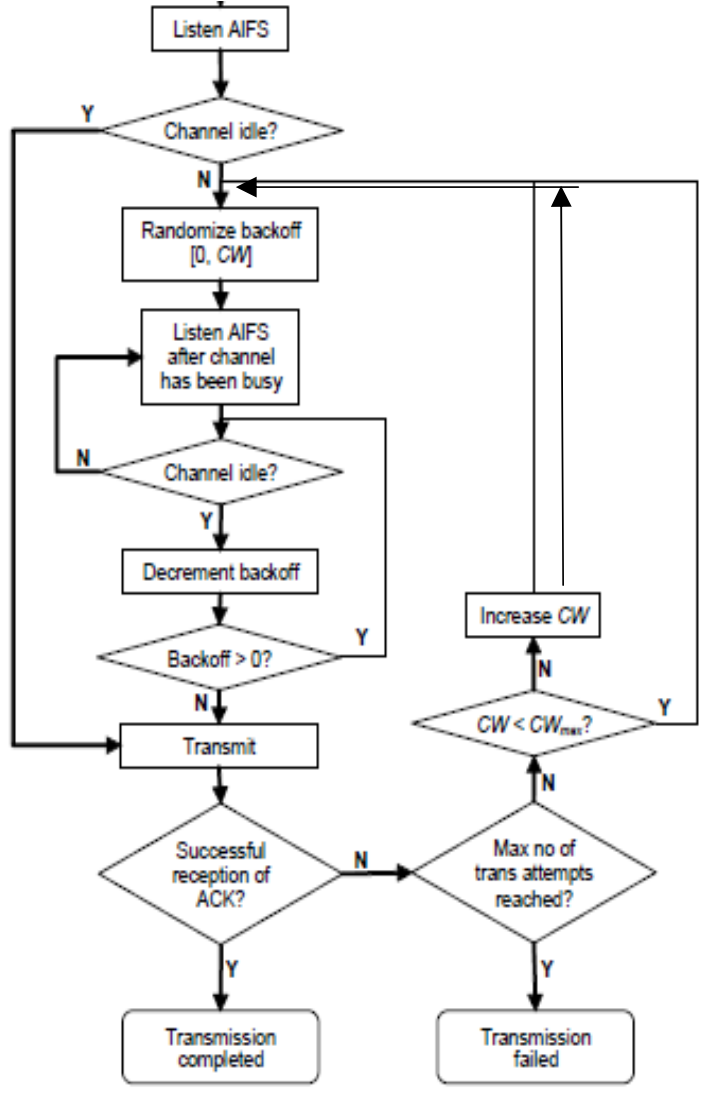

Gambar 5. Mekanisme akses media pada komunikasi unicast menurut IEEE 802.11-2012 (ETSI,2013)

Untuk menerapkan QoS, setiap node pada VANET memiliki 4 antrian data dengan 4 prioritas yang berbeda. Masing-masing kelompok memiliki AIFS dan parameter backoff yang berbeda. Semakin tinggi prioritasnya, semakin kecil nilai AIFS yang dimiliki. Perbedaan tersebut bertujuan supaya pesan-pesan dengan prioritas tinggi memiliki kesempatan menggunakan kanal komunikasi yang lebih besar dibandingkan dengan pesan dengan prioritas lebih rendah. Keempat antrian data tersebut dikenal dengan istilah Access Categories (AC). Tabel 2 menunjukkan 4 kelompok akses sesuai dengan IEEE $802.11 \mathrm{p}$, yaitu: Background (AC_BK), Best effort (AC_BE), Video (AC_VI), dan Voice (AC_VO), dengan nilai AIFS serta ukuran CW (Contention Window) masingmasing.

Tabel 2. AIFS dan ukuran CW dari tiap $A C$, IEEE 802.11p (ETSI,2013)

\begin{tabular}{|c|c|c|c|}
\hline AC & CW $_{\min }$ & CW $_{\max }$ & AlFS \\
\hline AC_V0 & 3 & 7 & $58 \mu \mathrm{s}$ \\
\hline AC_VI & 7 & 15 & $71 \mu \mathrm{s}$ \\
\hline AC_BE & 15 & 1023 & $110 \mu \mathrm{s}$ \\
\hline AC_BK & 15 & 1023 & $149 \mu \mathrm{s}$ \\
\hline
\end{tabular}

\subsection{STDMA}

Pada STDMA, pengaturan penggunaan kanal komunikasi menjadi tanggung jawab seluruh node jaringan. Node-node tersebut mengirimkan informasi berkala yang berisi tentang posisi masing-masing secara broadcast. Jadi, semua node yang menggunakan mekanisme ini harus dilengkapi dengan GPS.

Sesuai dengan TDMA, waktu dibagi menjadi beberapa frame dan frame dibagi menjadi beberapa slot. Semua node harus selalu berusaha melakukan sinkronisasi dengan mentukan awal dari frame yang sama. Ukuran dari 1 slot, umumnya, sama dengan durasi pengiriman 1 paket data. Untuk pengaturan penggunaan kanal, masing-masing node mengawali dengan mengirimkan report rate, yaitu informasi tentang jumlah posisi slot yang akan dibutuhkan untuk transmisi selama satu frame. Setelah itu dilanjutkan dengan fase inisialisasi, fase memasuki jaringan, fase frame pertama, dan fase operasi berkelanjutan.

\section{a. Fase inisialisasi}

Node mengamati kegiatan dari kanal selama satu periode frame.

\section{b. Fase memasuki jaringan}

Pada fase ini, tiap node memilih sendiri slotslot untuk melakukan transmisi berdasarkan aturan sebagai berikut :

1. Menghitung nilai Nominal Increment (NI) dengan membagi jumlah slot dalam 1 frame dengan report rate.

2. Pilih secara acak nilai Nominal Start Slot (NSS).

3. Menentukan Selection Interval (SI). SI adalah kumpulan beberapa slot yang berada di sekitar NSS dan jumlahnya adalah $20 \%$ dari $\mathrm{NI}$.

4. Slot yang akan digunakan untuk transmisi dipilih secara dari SI. Jika slot yang dipilih sudah ditempati, maka node harus memilih slot lain dalam SI. Apabila seluruh slot dalam SI sudah penuh, maka node akan memilih slot yang ditempati oleh node dengan posisi terjauh darinya. Slot yang terpilih disebut sebagai Nominal Transmission Slot (NTS).

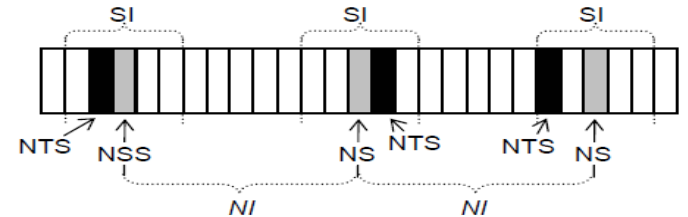

Gambar 6. Algoritma STDMA untuk fase frame pertama

\section{c. Fase frame pertama}

Pada fase ini, node memilih slot kedua untuk transmisi dengan menentukan Nominal Slot (NS) yang jaraknya sebesar NI slot dari NSS (seperti ditunjukkan pada gambar 5). NTS yang baru dipilih dari SI yang berada di sekitar NS. Proses penentuan NTS ini berulang sampai jumlah yang tercantum pada report rate terpenuhi. Setelah seluruh NTS untuk pengiriman selama 1 frame telah ditetapkan, node memasuki fase berikutnya. 


\section{d. Fase operasi berkelanjutan}

Nomor slot-slot atau NTS yang telah diperoleh selama frame pertama digunakan lagi untuk melakukan transmisi selama $n$ frame. Setelah itu, set NTS yang baru ditentukan lagi dipilih dari SI yang semula. Perubahan ini dilakukan untuk mengantisipasi perubahan-perubahan yang terjadi pada jaringan vehicular.

Berdasarkan penelitian dan simulasi yang dilakukan oleh Bilstrup dan kawan-kawan (Bilstrup et al., 2008), protokol STDMA menunjukkan tingkat kehandalan yang lebih baik dibanding dengan protokol yang diusulkan IEEE 802.11p, terutama pada saat kondisi trafik data yang padat. Paket data yang terbuang (packet drop) bisa mencapai $80 \%$ pada beberapa node jaringan yang menggunakan metode CSMA/802.11p.

\subsection{CMAC}

Prinsip protokol MAC dengan teknik cluster ini adalah dengan mengelompokkan kendaraankendaraan yang berdekatan dan bergerak ke arah yang sama. Protokol CMAC yang diusulkan oleh Rathore et al. (Rathore et al., 2010) menunjuk RSU sebagai pengelola kanal komunikasi. Area di sekitar RSU dibagi menjadi beberapa cluster kotak dengan jumlah tertentu. Gambar 7 menunjukkan contoh jaringan CMAC dengan 4 cluster. Batas dari tiap cluster ditandai dengan garis vertikal biru. Daerah yang berada pada perpotongan dua garis berbentuk oval adalah daerah handoff antar cluster.

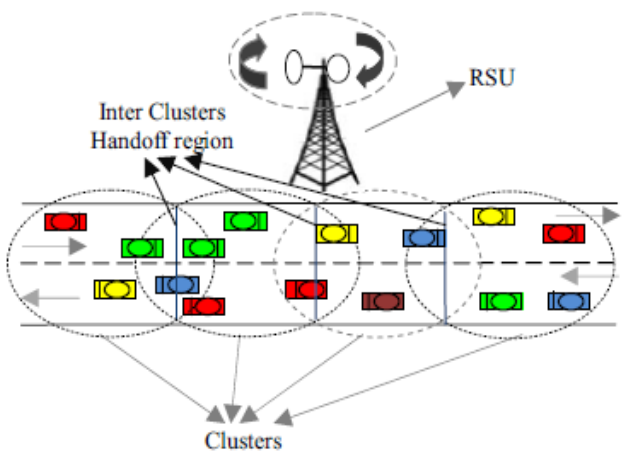

Gambar 7. Model protokol CMAC 4 cluster (Rathore, 2010)

Spektrum frekuensi yang tersedia dibagi menjadi beberapa daerah frekuensi yang dipisahkan oleh guard band. Tiap daerah frekuensi dibagi lagi menjadi beberapa slot waktu berukuran sama dan dipisahkan oleh guard time. Kanalkanal tersebut dapat dibagi menjadi 4 kelompok, yaitu : control band (CB), frequency band 1 (FB1), frequency band 2 (FB2), dan inter handoff band (IHB). CB digunakan untuk pengiriman pesanpesan kendali dan pesan yang berkaitan dengan keselamatan. FB1 adalah kelompok frekuensi yang dipakai oleh node-node untuk transmisi data. FB2 adalah grup frekuensi yang dipakai untuk komunikasi dalam cluster yang berdekatan dengan cluster yang mengunakan FB1. IHB berisi frekuensi-frekuensi yang dipakai pada area handoff.

Operasi akses media dari protokol RSU centric CMAC ini dapat dijelaskan sebagai berikut:

a. Tahap pendaftaran

RSU secara berkala mengirimkan pesan berisi identitas dan posisinya. Kendaraan yang memasuki area jangkauan suatu RSU dan menangkap sinyal periodik tersebut akan mengirimkan permintaan bergabung/ mendaftar ke RSU yang bersangkutan.

b. Tahap akses media

Kendaraan yang sudah terdaftar dan ingin berkomunikasi mengirimkan pesan permintaan akses media ke RSU melalui CB. Beberapa informasi yang tercantum dalam pesan tersebut adalah identitas pengirim, identitas tujuan, tipe aplikasi (safety atau nonsafety), posisi, kecepatan dan arah. RSU tidak akan memproses permintaan aplikasi non-safety, jika masih ada aplikasi penting di antrian dan belum dikerjakan. Apabila pihak yang dituju sibuk atau di luar jangkauan, maka RSU tidak akan mengalokasikan kanal ke node tersebut.

c. Tahap transmisi

Node akan mendapatkan hak penggunaan slot jika node yang dituju tidak sibuk dan berada dalam jangkauan. Slot yang telah dialokasikan oleh RSU tersebut dapat terus dipakai sampai transmisi selesai atau node berpindah cluster. Setelah RSU menerima pemberitahuan bahwa transmisi sudah selesai, maka RSU akan segera mengubah status kanal tersebut menjadi bebas.

Ada beberapa hal yang harus disimpan dan dipertahankan oleh RSU pada protokol ini. Yang pertama adalah adanya 2 antrian untuk pesan permintaan penggunaan kanal. Satu antrian untuk aplikasi yang bersifat darurat, yang biasanya menyangkut keselamatan, dan satu antrian untuk aplikasi non-safety. Pada protokol MAC VANET yang diusulkan IEEE $802.11 \mathrm{p}$, pengelompokan pesan berdasar prioritas ada pada tiap node jaringan. Yang kedua, RSU harus menyimpan tabel yang berisi informasi pasangan-pasangan node yang sedang berkomunikasi dan kanal yang digunakan. Misalkan, node A akan berkomunikasi dengan node $B$. RSU memeriksa tabel dan mengetahui bawa node $B$ sedang berkomunikasi dengan node C. Dalam kondisi tersebut, RSU tidak akan mengalokasikan kanal untuk digunakan oleh node A. Mekanisme ini dapat menghindarkan jaringan dari masalah hidden terminal dan exposed terminal.

EDCA sebagai protokol yang diusulkan oleh standar WAVE/ $802.11 \mathrm{p}$ dinilai memiliki beberapa kelemahan, antara lain tidak mampu menampilkan kinerja yang baik untuk trafik komunikasi data yang real-time (Bilstrup et al., 2008). Oleh karena itu, muncul beberapa usulan alternatif protokol MAC, seperti STDMA dan CMAC. STDMA yang berbasis TDMA dan menggunakan kendali akses tersebar ke semua node jaringan mampu menunjukkan 
kinerja yang baik pada saat trafik berat, ditinjau dari jumlah paket yang terbuang, kesempatan node-node mendapatkan akses ke media yang terbatas. Semua node pada STDMA dipastikan mendapatkan slot untuk melakukan transmisi sehingga tidak ada paket yang harus terbuang. Apabila ditinjau dari sisi waktu aksesnya, STDMA memiliki waktu akses yang dibatasi oleh waktu awal deteksi kesibukan kanal (listening period) ditambah dengan waktu penentuan NTS. CMAC dengan RSU sebagai pusat mampu menangani masalah hidden dan exposed terminal, namun memiliki kelemahan yaitu ketergantungan yang terlalu besar terhadap RSU. RSU harus memiliki kemampuan pengolahan dan komputasi yang baik. Sebagai jaringan ad-hoc, VANET seharusnya mampu membentuk koneksi dengan maupun tanpa bantuan RSU.

\section{KESIMPULAN}

Ada beberapa kesimpulan yang dapat diambil dari uraian mengenai VANET di atas, yaitu :

1. VANET adalah jaringan ad-hoc tanpa kabel yang anggotanya adalah kendaraankendaraan yang ada di jalan dan infrastruktur komunikasi yang ada di sekitar jalan raya. VANET ini dikembangkan dengan tujuan meningkatkan keselamatan pengguna jalan, menambah efisiensi lalu lintas, dan menyediakan kemudahan serta kenyamanan bagi pengendara, maupun penumpang kendaraan

2. Secara garis besar, VANET dapat mendukung berbagai aplikasi yang dapat dikelompokkan menjadi aplikasi berkaitan dengan keselamatan (safety application) dan aplikasi yang tidak berhubungan dengan keselamatan (non-safety application).

3. VANET memiliki beberapa karakteristik khusus yang membedakannya dari jaringan yang lain. Perbedaan tersebut terutama disebabkan karena tingginya mobilitas nodenode anggota VANET, kecepatan node tersebut bergerak, dan perubahan topologi jaringan VANET yang terus-menerus.

4. Karakateritik khusus dari VANET tersebut menyebabkan beberapa protokol untuk jaringan wireless ad hoc yang ada tidak sesuai diterapkan di VANET, termasuk protokol MAC.

5. Karena VANET dikembangkan untuk meningkat-kan keselamatan di jalan raya, maka protocol MAC untuk VANET harus memiliki kemampuan menangani pesanpesan penting yang berkaitan dengan keselamatan dan pengaturan lalu lintas dengan handal. Artinya, pesan dapat sampai ke pihak yang dituju dan dalam waktu pengiriman yang batas maksimalnya telah ditentukan (hard delay constraint).

6. Ketiga protocol MAC yang dibahas pada tulisan ini mewakili 3 kelompok mekanisme akses media, contention-based, contentionfree, campuran. EDCA yang diusulkan satandar IEEE 802.11p/WAVE berbasis CSMA/CD dan termasuk protocol MAC yang contention-based. STDMA termasuk contention-free, dan CMAC merupakan protocol MAC yang menggabungkan mekanisme contention-based dan contention-free.

\section{DAFTAR PUSTAKA}

[1] Almalag,M.S., M.C.Weigle, S.Olariu, MAC Protocols for VANET. Mobile Ad-hoc Networking: Cutting Edge Directions, $2^{\text {nd }}$ ed., IEEE Press, New Jersey, 2013, pp 599-618.

[2] ] Bilstrup,K., E.Uhlemann, E.G.Strom, U.Bilstrup, Evaluation of the IEEE 802.11p MAC Method for Vehicle- to-Vehicle Communication, Vehicular Technology Conference, September 2008.

[3 ] Dass, R., R.Sangwan, I.Girhdar, Vehicular Ad Hoc Networks, International Journal of Advanced Trends in Computer Science and Engineering, Volume 1, No.4, SeptemberOctober 2012, pp.121-129.

[4] ETSI (European Telecommunications Standards Institute, Intelligent Transport Systems (ITS); Access layer specification for Intelligent Transport Systems operating in the $5 \mathrm{GHz}$ frequency band, France, 2013.

[5] Gillani, S.A., P.A.Shah, A. Qayyum, H.B. Hasbullah, MAC Layer Challenges and Proposed Protocols for Vehicular Ad-hoc Networks, http://www.researchgate.net/publication/2786 81784, January 2015

[6] Kumar, V., S.Mishra, N.Chand, Applications of VANETS : Present and Future, Journal on Communications and Network, 2013, pp. 1215, (http://www.scirp.org/journal/cn).

[7] Leng, S., J.Guo, H.Fu, Y.Zhu, Q.Wang, Medium Access Control in Vehicular Ad-hoc Networks, in Vehicular Communications and Networks: Architectures, Protocols, Operation, and Deployment, Woodhead Publishing, UK, 2015, pp 39-70.

[8] Li, Y., An Overview of the DSRC/WAVE Technologi, in Quality, Reliability, Security, and Robustness in Heterogeneous Networks, Springer, Berlin, 2012, pp. 544-558.4

[9] Liang, W., Z. Li, H. Zhang, S. Wang, and R. Bie, Vehicular Ad Hoc Networks: Architectures, Research Issues, Methodologies, Challenges, and Trends, International Journal of Distributed Sensor Networks, Volume 2015, pp.1-11.

[10] Rathore, N.C., S.Verma, R.S.Tomar, G.S.Tomar, CMAC: A Cluster Based MAC Protocol for VANETs, 2010 International Conference on Computer Information Systems and Industrial Management Applications (CISIM), pp.563-568. 
[11] Raw,R.S., M.Kumar, N.Singh, Security Challenges, Issues, and Their Solutions for VANET, International Journal of Network Security \& Its Applications (IJNSA), Vol.5, No.5, September 2013,pp. 96-105.

[12] Rawat,D., G.Yan, Infrastructures in Vehicular Communications: Status, Challenges, and Perspectives in Advances in Vehicular Ad-hoc Networks : Development and Challenges, Infor-mation Science Reference, USA, 2010, pp. 1-18.
[13] Qian, Y., K.Lu, N.Moayeri, A Secure VANET MAC Protocol for DSRC Applications, IEEE Global Telecomunications Conference, 2008, pp 1-5.

[14] Teixeira,F.A., V.F. e Silva,, J.L.Leoni, J.F. Mace-do, J.M.S.Nogueira, Vehicular Networks Using IEEE 802.11p Standard: An Experimental Analysis, Vehicular Communications 1, 2014, pp 91-96. 